\title{
UNUSUAL FINDING IN A RIGHT ILIAC FOSSA MASS
}

\section{MA Kurer, Trust Grade in General Surgery Furness General Hospital}

\section{INTRODUCTION}

Inflammation of solitary caecal diverticula is an uncommon pathological condition. Preoperatively the condition is almost indistinguishable from appendicitis, and is often confused with carcinoma of the caecum during operation. The typical patient is male, Asian, and in the fourth decade of life. Our case was unusual in that the patient was a 26-year-old Caucasian man.

\section{CASE REPORT}

A 26-year-old white man was admitted to the hospital with a history of three days of constant abdominal pain, which started centrally and shifted to the right lower quadrant. He had had recurrent episodes of abdominal pain for six months prior to his presentation. He had no vomiting or change of bowel habit, and no urinary symptoms.

Physical examination revealed a temperature of $37.9^{\circ} \mathrm{C}$, heart rate 90 beats per minute, and blood pressure 130/80 $\mathrm{mmHg}$. Marked right iliac fossa tenderness with rebound was the only significant physical finding. Digital rectal examination was normal. Apart from a white cell count of 12.9 and C-reactive protein of 42 , other initial investigations including urinalysis were within normal limits.

A presumptive diagnosis of appendicitis was made, and during surgery abdominal palpation revealed a right iliac fossa (RIF) mass. There was a small amount of clear free fluid. The appendix was normal, as was the terminal ileum. There was a solitary diverticulum projecting from the medial aspect of the caecum and forming an inflammatory mass with the omentum. A limited right hemicolectomy was performed and the patient had an uneventful recovery. Examination of the resected specimen showed a solitary caecal diverticulitis with perforation.

\section{DISCUSSION}

The first case of solitary caecal diverticulum was reported in 1863. More than 500 cases have been recorded since then. The condition is uncommon, seen in only 10 of 5,000 radiological examinations, with a greater incidence in Oriental people ${ }^{(1)}$. The condition is unrelated to the wellknown multiple colonic diverticular disease which is a common disorder in the west. A reported experience of caecal diverticulitis from Singapore has suggested that the average age of presentation is 36 years (3-74) with male predominance $^{(2)}$. Nearly $80 \%$ of the caecal diverticula are situated $1-2 \mathrm{~cm}$ from the ileocaecal valve ${ }^{(3)}$. They are usually solitary. Approximately $60 \%$ of solitary caecal diverticula arise from the anterior aspect of the caecum, so that when inflammation occurs it tends to result in perforation and peritonitis. A diverticulum situated posteriorly, however, may produce a mass without generalised peritonitis, simulating perforation of a caecal carcinoma. Correct preoperative diagnosis of acute caecal diverticulitis is only made in about $9 \%$ of cases, and most of these patients have had previous appendectomy. Even peroperatively, the correct diagnosis was only made in about $65 \%$ of $\operatorname{cases}^{(4)}$.

Although the aetiology of solitary caecal diverticula is uncertain, congenital origin is widely accepted. The theory suggests that an outgrowth of the caecum develops in the sixth week and atrophies by about the seventh week. If this 'transient appendix' fails to disappear, a diverticulum or a duplication of the appendix results ${ }^{(5-7)}$. This concept is supported by the facts that the condition has been reported in a three-year-old $\operatorname{girl}^{(8)}$, the incidence does not increase with age $^{(9)}$, and it is a true type of diverticulum. Most authors agree that, preoperatively, it is almost impossible to distinguish between acute solitary caecal diverticulitis and acute appendicitis, even retrospectively ${ }^{(10)}$. However, some authors believe that the longer duration of illness ${ }^{(11)}$, the absence of nausea and vomiting ${ }^{(3)}$, and the relative lack of toxicity ${ }^{(12)}$ are features of caecal diverticulitis.

It has been suggested that chronic recurrent abdominal pain due to inflammation of a solitary caecal diverticulum might be responsible for the syndrome of 'grumbling appendix'. The outcome of chronic recurrent abdominal pain has been studied by many surgeons as well as gynaecologists, often using laparoscopy, and caecal diverticula have not been encountered as a cause. Adhesions, chronic and acute appendicitis, inguinal hernia, and endometriosis were the main causes of chronic recurrent abdominal pain ${ }^{(13)}$.

There is no standard surgical procedure for treatment of an inflamed solitary caecal diverticulum. The extent of the inflammation, the experience of the surgeon, and the confidence in the intraoperative diagnosis determine the procedure. Procedures range from simple diverticulectomy to right hemi-colectomy, with appendicectomy when only a diverticulum is removed ${ }^{(1)}$. Management of a solitary caecal diverticulum when it is an incidental finding is more controversial. The condition may be encountered preoperatively, eg following a barium enema examination, in which case it is probably sensible to do nothing ${ }^{(15)}$. The decision as to whether to interfere or not, in asymptomatic solitary caecal diverticulum, should be based on the chances of it becoming inflamed or developing other complications.

Although Canver and Freier claimed that $14 \%$ of caecal diverticula will ultimately become inflamed ${ }^{(14)}$, they did not make it clear how they came to their conclusion. Perhaps the more important question is what should we do if a solitary caecal diverticulum is found incidentally at laparotomy? 
Langdon advised either excision or inversion ${ }^{(15)}$, but it should be emphasised that the problem is uncommon, and this approach is not evidence-based.

\section{REFERENCES}

1 Williams KL. Acute solitary ulcers and acute diverticulitis of the caecum and ascending colon. Br J Surg 1960;47:351-8

2 Tam EC, Tung KH, Wee A. Diverticulitis of caecum and ascending colon in Singapore. J R Coll Surg Edinb $1984 ; 29: 373-6$

3 Lauredsen J, Ross FP. Acute diverticulitis of caecum. Report of four cases and review of 153 surgical cases. AMA Arch Surg 1952;64:320-30

4 Wuble EJ, Lee WC. Caecal diverticulitis: changing trends in management. South Med J 1988;81:313-6

5 Gladstone RJ, Wakeley CPG. The relative frequency of the various positions of the vermiform appendix as ascertained by an analysis of 3000 cases, with an account of its development. Br J Surg 1923-24;11:503-20

6 Cave AJE. Appendix vermiformis duplex. J Anat 1936;70:283-92
7 Waugh TR. Appendix vermiformis duplex. Arch Surg $1941 ; 42: 311-20$

8 Odqvist B, Petren T. Ein Fall von angeborener Divertikelbildung des Blinddarms. Virchows Arch [Pathol Anat] $1931 ; 280: 581-6$

9 Hughes LE. Postmortem survey of diverticulum disease of the colon. I: diverticulosis and diverticulitis. Gut 1969; 10:336-44

10 Laimon H, Cohn P. Diverticulitis of the caecum. A report of eight cases. Am J Surg 1962;103:146-9

11 Rigler RG, Cherry JW. Diverticulitis of the caecum. Preoperative diagnosis. Am Surg 1960;26:405-8

12 Anscombe AR, Keddie NC, Schofield PF. Solitary ulcers and diverticulitis of the caecum. Br J Surg 1967;54:553-7

13 Miller K, Mayer E, Moritz E. The role of laparoscopy in chronic recurrent abdominal pain. Am J Surg 1996;172:353-7

14 Canver C, Freier T. Management of cecal diverticulitis. Am J Gastroentrol. 1986;81:1104-6

15 Langdon A. Solitary diverticulitis of the right colon. Can J Surg 1982;25:579-81 